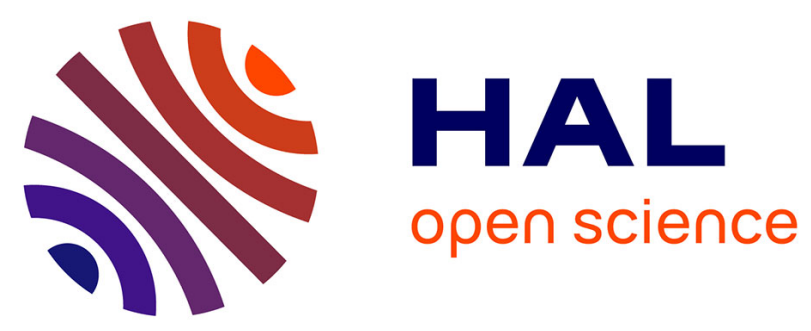

\title{
Dispersion measurement of platinum supported on Yttria-Stabilised Zirconia by pulse $\mathbf{H}-2$ chemisorption
}

\author{
M. Alves Fortunato, Daniel Aubert, Chloé Capdeillayre, C. Daniel,
} Abdelkader Hadjar, Agnès Princivalle, Christian Guizard, P. Vernoux

\section{- To cite this version:}

M. Alves Fortunato, Daniel Aubert, Chloé Capdeillayre, C. Daniel, Abdelkader Hadjar, et al.. Dispersion measurement of platinum supported on Yttria-Stabilised Zirconia by pulse H-2 chemisorption. Applied Catalysis A : General, 2011, 403 (1-2), pp.18-24. 10.1016/j.apcata.2011.06.005 . hal00933241

\section{HAL Id: hal-00933241 \\ https://hal.science/hal-00933241}

Submitted on 18 Aug 2021

HAL is a multi-disciplinary open access archive for the deposit and dissemination of scientific research documents, whether they are published or not. The documents may come from teaching and research institutions in France or abroad, or from public or private research centers.
L'archive ouverte pluridisciplinaire HAL, est destinée au dépôt et à la diffusion de documents scientifiques de niveau recherche, publiés ou non, émanant des établissements d'enseignement et de recherche français ou étrangers, des laboratoires publics ou privés. 


\title{
Dispersion measurement of platinum supported on Yttria-Stabilised Zirconia by pulse $\mathrm{H}_{2}$ chemisorption
}

\author{
M. Alves Fortunato ${ }^{\mathrm{a}}$, D. Aubert ${ }^{\mathrm{a}}$, C. Capdeillayre ${ }^{\mathrm{a}}$, C. Daniel $^{\mathrm{b}}$, A. Hadjar $^{\mathrm{b}}$, A. Princivalle $^{\mathrm{a}}$, \\ C. Guizard ${ }^{\mathrm{a}}, \mathrm{P}$. Vernoux ${ }^{\mathrm{a}, \mathrm{b}, *}$ \\ ${ }^{a}$ Laboratoire de Synthèse et Fonctionnalisation des Céramiques, UMR3080, CNRS/Saint-Gobain CREE, 550, Av. Alphonse Jauffret, 84306 Cavaillon Cedex, France \\ b Université Lyon 1, CNRS, UMR 5256, IRCELYON, Institut de Recherches sur la Catalyse et l'Environnement de Lyon, 2 Avenue Albert Einstein, F-69626 Villeurbanne, France
}

\begin{abstract}
Platinum nanoparticles were dispersed by wet impregnation on $\mathrm{YSZ}\left(8 \mathrm{~mol} \% \mathrm{Y}_{2} \mathrm{O}_{3}\right)$ an ionically conducting support. The Pt dispersion of a series of catalysts was determined by using $\mathrm{H}_{2}$ pulse chemisorption. Temperature Programmed Reduction (TPR) experiments were performed to characterize the pre-reduction step before dispersion measurements. Finally, a fast and reliable procedure was defined for the Pt dispersion measurements consisting in a pre-reduction step in hydrogen at $500^{\circ} \mathrm{C}$ before the $\mathrm{H}_{2}$ pulse chemisorption performed at $-28^{\circ} \mathrm{C}$. Reproducible Pt dispersion values were obtained in good agreement with those measured by pulse $\mathrm{CO}$ chemisorptions and static volumetric titration. In addition, the combination of Diffuse Reflectance Infrared Fourier Transform (DRIFT) spectroscopy and TPR has evidenced the role of surface oxygen vacancies on YSZ support for both $\mathrm{H}_{2}$ and $\mathrm{CO}$ chemisorptions.
\end{abstract}

\section{Introduction}

Supported metal catalysts are widely used in industry. Their catalytic activity is proportional to the active surface area per volume of catalyst [1]. Therefore, the dispersion of metal particles over the support is an important parameter to be controlled since it determines the quantity of metal particles available on the support surface to participate in a reaction. The most commonly used methods to measure the metal dispersion are chemisorption techniques which can be static or dynamic, using $\mathrm{H}_{2}$ or $\mathrm{CO}$ as a gas probe $[2,3]$. The probe molecule adsorbs on the metal particles present on the surface and, knowing the stoichiometry of the chemisorption reaction, one can determine the amount of metal particles accessible to the gas. In addition, chemisorption techniques can be fast, easy to implement and require a relatively simple apparatus.

Physical methods can also be used since the dispersion is related with the mean particle size and surface area [3]. Techniques as Xray diffraction (XRD) and High-Resolution Transmission Electron Microscopy (HRTEM) may provide the measurement of the metallic particles size and distributions. Nevertheless, it is difficult to obtain quantitative results when the size distribution of metallic particles

\footnotetext{
* Corresponding author at: Institut de Recherches sur la Catalyse et l'Environnement de Lyon (IRCELYON), 2 Avenue Albert Einstein, F-69626 Villeurbanne Cedex, France. Tel.: +33 4 72431587; fax: +33 472431695.

E-mail address: philippe.vernoux@ircelyon.univ-lyon1.fr (P. Vernoux).
}

is wide which is common in real processes. Therefore, chemical methods should be used when analysing poly-dispersed catalysts.

However, chemisorption methods may not produce reliable and reproductive results of metal dispersion when the supports are also able to chemisorb the probe molecule. This is the case of some mixed-oxides $[2,4]$ such as $\mathrm{CeO}_{2}-\mathrm{ZrO}_{2}$. In these materials, the hydrogen molecule is able to dissociate over the Pt nanoparticles and then migrate onto the support, in a process called spillover [4]. For instance, Perrichon et al. [2] measured the metal dispersion of Pt supported on $\mathrm{CeO}_{2}-\mathrm{ZrO}_{2}$ using a volumetric (static) chemisorption method. They demonstrated the importance to determine the appropriate parameters of the dispersion measurement in order to avoid artefacts due to $\mathrm{H}_{2}$ spillover onto the support. The main parameters to be adjusted are the temperature of reduction pretreatment and that of the $\mathrm{H}_{2}$ chemisorption. However, the use of pulse chemisorption methods is more convenient since they are faster and do not require vacuum systems leading to less expensive measurements.

Yttria-Stabilised Zirconia (YSZ) is known to be an $\mathrm{O}^{2-}$ conductor due to the presence oxygen vacancies inside its crystallographic structure. This oxide has been extensively studied as a material for oxygen sensors and fuel cells [5]. Recently, YSZ has received attention as a catalytic support especially in studies of Electrochemical Promotion of Catalysis (EPOC) also called NEMCA (Non Faradaic Electrochemical Modification of the Catalytic Activity) effect [5]. Vayenas et al. [6] were the first to show that the migration of ionic species from a solid electrolyte to the catalyst surface induced by 
Table 1

Main characteristics of catalysts.

\begin{tabular}{lll}
\hline Catalysts & Pt loading $(w t \%)$ & Specific area $\left(\mathrm{m}^{2} / \mathrm{g}\right)$ \\
\hline A-PtTZ8 & 0.35 & 14 \\
B-PtTZ8 & 0.7 & 13 \\
C-PtTZ8 & 1.4 & 13 \\
Pt-TZ0 & 0.8 & 13 \\
\hline
\end{tabular}

electrical polarizations can improve catalytic performances. EPOC can be associated with the concept of Strong Metal Support Interaction (SMSI) [7] in which ions or electrons from the support can chemically interact with the metal particles, altering its catalytic properties. Recently, Vayenas et al. [6,8] have described EPOC as an electrically controlled SMSI. An interesting review by Prof. Haller [9] summarized that both concepts can be interpreted in terms of metallic work function modification and metal surface decoration by ionic species coming from the bulk support. We recently [10] found that EPOC can be thermally induced without any electrical polarization by using nanoparticles of metallic catalysts supported on ionically conducting ceramics, such as YSZ. This phenomenon adds to the appeal of using YSZ as an alternative support in various heterogeneous catalyses.

The aim of this paper is to determine an appropriate and fast method to measure the dispersion of platinum over YttriumStabilised Zirconia, $8 \mathrm{~mol} \% \mathrm{Y}_{2} \mathrm{O}_{3}-\mathrm{ZrO}_{2}$ (YSZ), as well as to characterize the Pt/YSZ interactions. Commercial YSZ supports commonly exhibit low specific surface areas, i.e. around $10 \mathrm{~m}^{2} / \mathrm{g}$. Therefore, the dispersion of Pt nanoparticles on YSZ surface is rather low and heterogeneous. Then, a reliable measurement of this dispersion is difficult to achieve. Hydrogen pulse chemisorption was the selected method because measurements are much faster than the volumetric method and does not require ultra low vacuum systems.

HR-TEM and pulse chemisorption (dynamic adsorption) techniques were used and compared for the measurement of metal dispersion of Pt supported on YSZ. This chemical technique was performed by injecting known doses of the reactive probe gas, $\mathrm{H}_{2}$ or $\mathrm{CO}$, on a catalyst. These probe molecules were used and compared because they exhibit different adsorption behaviours $[11,12]$. Pt dispersion measurements were performed at different temperatures of pre-treatment and chemisorptions. Temperature Programmed Reduction (TPR) and Diffuse Reflectance Infrared Fourier Transform spectroscopy (DRIFTS) were performed to investigate the Pt/YSZ interactions.

\section{Experimental}

\subsection{Catalyst preparation}

Platinum nanoparticles were dispersed over $8 \mathrm{~mol} \%$ YttriaStabilised Zirconia (TZ8) or pure zirconia $\left(\mathrm{ZrO}_{2}, \mathrm{TZ0}\right)$ both supplied by $\mathrm{TOSOH}$. The platinum precursor was diammineplatinum(II) nitrite, $\left(\mathrm{NH}_{3}\right)_{2} \mathrm{Pt}\left(\mathrm{NO}_{2}\right)_{2}$. The catalysts were prepared by incipient wet impregnation method in order to obtain different Pt loadings. The impregnation was performed at $70^{\circ} \mathrm{C}$ for 70 min under stirring at atmospheric pressure. Then, the excess water was eliminated at $40^{\circ} \mathrm{C}$ under vacuum and the remaining powder was dried at $110^{\circ} \mathrm{C}$ overnight. Finally, the catalysts were calcinated at $550^{\circ} \mathrm{C}$ for $1 \mathrm{~h}$ in air flow, and then reduced under flowing $100 \% \mathrm{H}_{2}$ at $500{ }^{\circ} \mathrm{C}$ for $1 \mathrm{~h}$. The prepared catalysts are listed in Table 1.

\subsection{Catalysts characterizations}

The Pt loading was measured by inductively coupled plasmaemission spectroscopy, ICP-OES (Varian). The specific surface area
(SSA) was determined by the BET method (Quantachrom, Mod. Nova 2000), using nitrogen adsorption at $-195^{\circ} \mathrm{C}$. The specific surface area did not present any significant difference before and after impregnation and was found to be around $13 \mathrm{~m}^{2} / \mathrm{g}$. The catalysts were observed by HRTEM (High-Resolution Transmission Electronic Microscopy, JEOL 2010 LaB6) for investigating the morphology and size of Pt particles. Replica techniques were used for sample preparation. Catalysts were dispersed in ethanol and deposited on a mica film and covered with a carbon layer. Then, TZ8 and TZO supports as well as the film of mica were dissolved in HF solution for $24 \mathrm{~h}$ whereas Pt particles remainder fixed on the carbon film. Then, these particles were directly observed by HRTEM. The use of Image J software allowed for the determination of $\mathrm{Pt}$ particles size distribution.

\subsection{Temperature Programmed Reduction (TPR)}

TPR measurements were performed by using an AutoChemII 2920 station from Micromeritics with $200 \mathrm{mg}$ of sample placed in a U-shaped quartz reactor. The catalyst was pretreated with a flow of $\mathrm{O}_{2}$ at $500{ }^{\circ} \mathrm{C}$ for $1 \mathrm{~h}$ and then cooled down to room temperature. TPR analysis was carried out using 3\% $\mathrm{H}_{2}$ in argon as a reducing gas, with a gas flow of $30 \mathrm{~mL} / \mathrm{min}$. The temperature was raised to $500^{\circ} \mathrm{C}$ at $10^{\circ} \mathrm{C} / \mathrm{min}$. Hydrogen consumption was detected by a thermal conductivity detector (TCD). A water trap was located before the TCD in order to avoid any $\mathrm{H}_{2}$ signal perturbation. The sample temperature, the position of valves as well as the TCD signal were controlled and monitored by a computer equipped with the Micromeritics AutoChemII software. TCD data were analysed using Origin Pro 8 software. The TCD was calibrated by introducing different concentrations of $\mathrm{H}_{2}$ in argon (from 0 to 5\%). TCD signals collected were used to obtain a calibration curve which was introduced in the Micromeritics AutoChem II software before TPR run. The deconvolution and integration of the TPR peaks were performed using the Origin Pro 8 software. Peaks of $\mathrm{H}_{2}$ consumption were assumed to be Gaussian. The peak analyser function of the Origin Pro 8 software allows fitting three TPR peaks as well as the baseline. The software clearly separates three peaks and achieves an accurate cumulative fit of the TPR spectra with an adjusted $R$ square higher than 0.99 . The area of each fitted peak, which was calculated by Origin Pro 8, represents the quantities of $\mathrm{H}_{2}$ consumed exposed in Table 2.

\subsection{Pulse chemisorption}

Pulse chemisorption was also performed by an AutoChemII 2920 station from Micromeritics. The samples ( $200 \mathrm{mg}$ ), placed in a U-shaped quartz reactor with an inner diameter of $0.5 \mathrm{~cm}$, were pretreated under $40 \% \mathrm{H}_{2}$ in He at various temperatures $(200,300$, 400 and $500^{\circ} \mathrm{C}$ ) for $2 \mathrm{~h}$. Then, catalysts were cooled down to $400^{\circ} \mathrm{C}$ under an argon flow of $50 \mathrm{~mL} / \mathrm{min}$, and maintain at this temperature for $3 \mathrm{~h}$ before further cooling to the desired temperature for chemisorptions in order to clean the Pt surface and to avoid the presence of residual adsorbed hydrogen. Pulse chemisorption was performed at two different temperatures $-28^{\circ} \mathrm{C}$ and $35^{\circ} \mathrm{C}$. A cryocooler from Micromeritics was used to inject liquid nitrogen to cool down the sample at $-28^{\circ} \mathrm{C}$. The volume of the injection loop was $0.5 \mathrm{~cm}^{3}$. The carrier gas was $\mathrm{Ar}$ in the case of $\mathrm{H}_{2}$ pulses $\left(3 \% \mathrm{H}_{2}\right.$ in Ar, AIR LIQUIDE, 99,99\% purity) and He for CO injection (1\% CO in $\mathrm{He}$, AIR LIQUIDE, 99.99\% purity). Pulses of $\mathrm{H}_{2}$ and $\mathrm{CO}$ were injected in the catalytic reactor corresponding to 0.47 and $0.16 \mu \mathrm{mol}$ of $\mathrm{H}_{2}$ and $\mathrm{CO}$, respectively. The $\mathrm{H}_{2}$ and $\mathrm{CO}$ consumptions were measured with the same TCD used for TPR equipped with water trap. Pulses injection, sample temperature and TCD signals were controlled and 
Table 2

Results of Temperature-Programmed Reduction (TPR) experiments.

\begin{tabular}{|c|c|c|c|c|c|c|c|c|}
\hline \multirow[t]{2}{*}{ Samples } & \multicolumn{3}{|c|}{ Temperature of $\mathrm{H}_{2}$ consumption peaks $\left({ }^{\circ} \mathrm{C}\right)$} & \multicolumn{3}{|c|}{$\mathrm{H}_{2}$ consumed $(\mu \mathrm{mol})$} & \multirow{2}{*}{$\begin{array}{l}\text { Oxygen vacancies } \\
\text { concentration in } \\
\text { interaction with } \mathrm{Pt} \\
\text { nanoparticles }\left(\mathrm{m}^{-2}\right) \\
\text { LT1 }\end{array}$} & \multirow{2}{*}{$\begin{array}{l}\text { Ratio } \mathrm{H}_{2} / \mathrm{Pt} \text {, total } \\
\text { LT1 }\end{array}$} \\
\hline & LT1 & LT2 & HT & LT1 & LT2 & HT & & \\
\hline A-PtTZ8 & 125 & 197 & 343 & 1.5 & 2.6 & 0.3 & $3.5 \times 10^{17}$ & 0.41 \\
\hline B-PtTZ8 & 120 & 192 & 350 & 1.3 & 3.9 & 0.23 & $3 \times 10^{17}$ & 0.18 \\
\hline C-PtTZ8 & 113 & 190 & 351 & 0.72 & 3.7 & 0.14 & $1.7 \times 10^{17}$ & 0.05 \\
\hline
\end{tabular}

monitored by a computer equipped with the software Micromeritics AutoChemII. TCD data were analysed using the Origin software.

\subsection{Diffuse Reflectance Infrared Fourier Transform (DRIFT) experiments}

DRIFTS experiments were performed with a classical high temperature DRIFT cell with $\mathrm{KBr}$ windows, with a collector assembly from Harrick Scientific Corporation (Praying Mantis ${ }^{\mathrm{TM}}$ ). We used a support in inox and introduced SiC powder in the catalytic bed, in order to homogenise the temperature in the cell and at the surface of the sample bed. The amount of catalyst (about $100 \mathrm{mg}$ ) introduced in the inox sample holder cup provided suitable layer thickness in order to assume a semi-infinite thick sample. All catalysts were sieved to have particles of $100 \mu \mathrm{m}$ diameter, in order to reduce specular reflexion contribution. The catalysts were pretreated with a first reduction of $40 \% \mathrm{H}_{2}-\mathrm{Ar}, 50 \mathrm{~mL} / \mathrm{min}$, at $500{ }^{\circ} \mathrm{C}$ for $2 \mathrm{~h}$. Then, the sample was cooled to $25^{\circ} \mathrm{C}$ and purged under Argon for $30 \mathrm{~min}$. The $\mathrm{CO}$ adsorption was performed at $25^{\circ} \mathrm{C}$ in a gas flow of $20 \%$ CO in Ar (AIR LIQUIDE, purity 99.999\%), $50 \mathrm{~mL} / \mathrm{min}$, for $30 \mathrm{~min}$. Finally, the system was purged under argon for $30 \mathrm{~min}$ and the temperature was raised to $700^{\circ} \mathrm{C}$ with a ramp of $10^{\circ} \mathrm{C} / \mathrm{min}$. The spectrophotometer used is a Nicolet 6700 (ThermoFishcer Scientific) with a MCT detector. The DRIFT spectra were recorded with a resolution of $4 \mathrm{~cm}^{-1}$ and 32 scans accumulation. The results presented here are already considering the background measurement with $\mathrm{KBr}$.

\section{Results and discussions}

\subsection{High-Resolution Transmission Electron Microscopy (HRTEM)}

The HRTEM images of samples A-PtTZ8, B-PtTZ8 and C-PtTZ8, calcinated at $500^{\circ} \mathrm{C}$ in air and reduced at $500^{\circ} \mathrm{C}$ for $1 \mathrm{~h}$ in pure $\mathrm{H}_{2}$, are shown in Fig. 1. The images revealed a wide Pt particle size distribution starting from $1 \mathrm{~nm}$ up to $30 \mathrm{~nm}$. The shape of all 2D images of Pt particles looks like small disks. Therefore, their 3D shape is probably cylindrical or spherical. We have evaluated the platinum particles size distribution of A, B and C-PtTZ8 from more than 200 nanoparticles over 5 different TEM micrographs for each sample (Fig. 2). This statistic determination of the mean diameter is not accurate due to the heterogeneity of the samples. The statistic mean particle size is between $3 \mathrm{~nm}$ and $4 \mathrm{~nm}$ for A-PtTZ8 and B-PtTZ8 samples. The catalyst C-PtTZ8 presents the largest range of distribution, with a mean value slightly higher of $5.5 \mathrm{~nm}$. Nevertheless, considering only particles size in the range $0-4 \mathrm{~nm}$ which is predominant (at least 60\%), the mean diameter rank changes and becomes 1.92, 1.38 and $1.4 \mathrm{~nm}$ for A-PtTZ8, B-PtTZ8 and CPtTZ8, respectively. Let us note that agglomerates of around $15 \mathrm{~nm}$ exist for all catalysts. Nevertheless, the quantity of large Pt particles seems to increase with the Pt loading. For instance, particles with diameter higher than $20 \mathrm{~nm}$ only exist on C-PtTZ8, containing the highest Pt loading. We estimated the dispersion by the reverse of the mean particle size expressed in $\mathrm{nm}$ by assuming that 3D particles are spherical and a statistic mean diameter between 3 and
$5.5 \mathrm{~nm}$. We obtained values in the range of $18-33 \%$ that can only be considered as indicative.

\subsection{Temperature Programmed Reduction}

The reducibility of Pt/YSZ catalysts was investigated by Temperature-Programmed Reduction (TPR). Hydrogen TPR profiles obtained for the preoxidized Pt/YSZ catalysts are shown in Fig. 3. Three peaks of hydrogen consumption can be clearly identified. The large part of the $\mathrm{H}_{2}$ consumption takes place at low temperatures from $50^{\circ} \mathrm{C}$ up to $300^{\circ} \mathrm{C}$. Two low-temperature consumption peaks, denoted as LT1 and LT2, are centred at around $100-120^{\circ} \mathrm{C}$ and 200-225 ${ }^{\circ} \mathrm{C}$, respectively. Chen et al. [11] have performed TPR on similar Pt/YSZ (0.5 wt\%) catalysts and also found two $\mathrm{H}_{2}$ consumption peaks centred at $80^{\circ} \mathrm{C}$ and $159^{\circ} \mathrm{C}$. These authors attributed these two temperature peaks to the reduction of platinum oxides. They suggested that the first, and minor peak, could be due to $\mathrm{H}_{2}$ adsorption on oxygen vacancies in contact with Pt particles, then promoting the reduction of the perimeter platinum oxides. This assumption is also supported by the study of Dow et al. [13] who performed TPR on $\mathrm{Cu} / \mathrm{YSZ}$ samples. These authors also linked the low-temperature $\mathrm{H}_{2}$ consumption with surface $\mathrm{YSZ}$ oxygen vacancies which are in contact with $\mathrm{Cu}$ particles. Our results confirm the presence of these two peaks, corresponding to two different mechanisms of platinum oxides reduction by hydrogen. Referring to Refs. $[11,13]$ and assuming that the $\mathrm{H}_{2}$ consumption of the LT1 peak is linked to $\mathrm{H}_{2}$ adsorption on oxygen vacancies located on the surrounding of Pt particles, the ratio between this LT1 $\mathrm{H}_{2}$ consumption and the overall quantity of Pt in the catalyst (Table 2) gives an indication of the interaction level between Pt particles and surface YSZ oxygen vacancies. Table 2 shows that A-PtTZ8 with $0.35 \mathrm{wt} \%$ of Pt presents the highest concentration of oxygen vacancies in contact with Pt particles. It was observed that temperature values corresponding to the two low-temperature consumption peaks decreased when the Pt loading increases (Fig. 3 and Table 2). This could be due to the increase of Pt size particles with Pt loading which weakens the strength of $\mathrm{Pt}-\mathrm{O}$ bonds [14]. The surface concentration of oxygen vacancies in interaction with Pt particles, estimated from LT1 area, decreased with the Pt loading (Table 2). This concentration of oxygen vacancies varies between $1.7 \times 10^{17}$ and $3.5 \times 10^{17}$ vacancies $/ \mathrm{m}^{2}$. These values are similar to those of reference [13] recorded on Cu/YSZ samples. Katsaounis et al. [15] evidenced, by ${ }^{18} \mathrm{O}_{2}$ TPD, the existence of weakly bonded oxygen species chemisorbed on Pt which desorbed at around $100-160^{\circ} \mathrm{C}$. This oxygen adsorption state, described as very active for catalysis, was linked with three-phase boundaries Pt-YSZ-gas. These active sites could be similar to those of the LT1 peak.

TPR spectra revealed also a high-temperature $\mathrm{H}_{2}$ consumption peak (denoted as HT) at around $355-400^{\circ} \mathrm{C}$. The HT peak could be due to the spillover of $\mathrm{H}_{2}$ from the reduced Pt particles toward the YSZ surface. These hydrogen species could adsorb on available oxygen vacancies and/or could react with hydroxyl groups of YSZ. This $\mathrm{H}_{2}$ consumption of this HT peak is low and decreases with Pt loading but can overestimate the Pt dispersion value. For instance, for the catalyst B-PtTZ8 which contains $0.7 \mathrm{wt} \%$ of Pt, the $\mathrm{HT} \mathrm{H}_{2}$ con- 

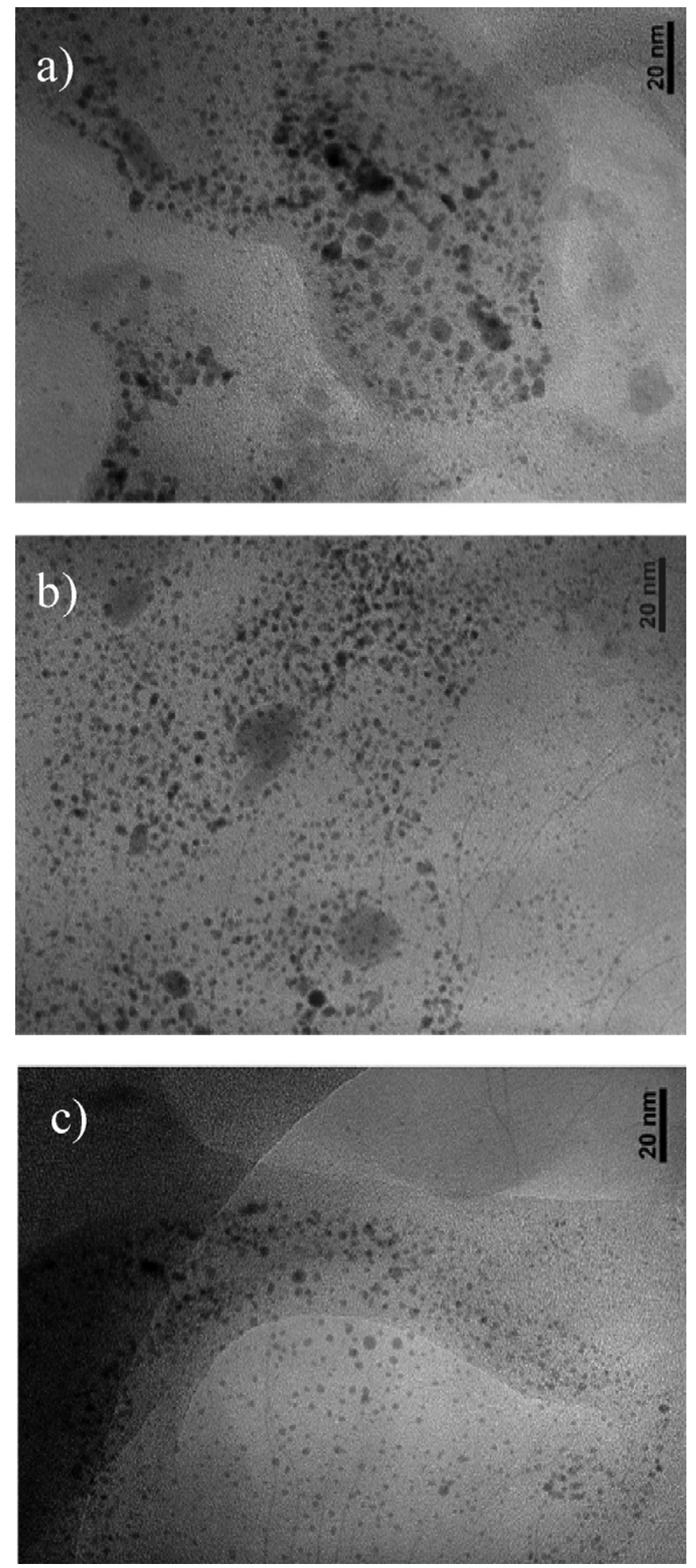

Fig. 1. TEM images of Pt/YSZ catalysts: (a) A-PtTZ8, (b) B-PtTZ8 and (c) C-PtTZ8.

sumption peak could introduce a strong error in the Pt dispersion value of the order of $20 \%$ considering an estimated value of the dispersion of around $20 \%$. Of course, this error will be much higher for A-PtTZ8.

\subsection{Measurement of Pt dispersion by pulse $\mathrm{H}_{2}$-chemisorption}

The sample B-PtTZ8 was used in a first step to determine the most suitable parameters for obtaining reliable Pt dispersion val-

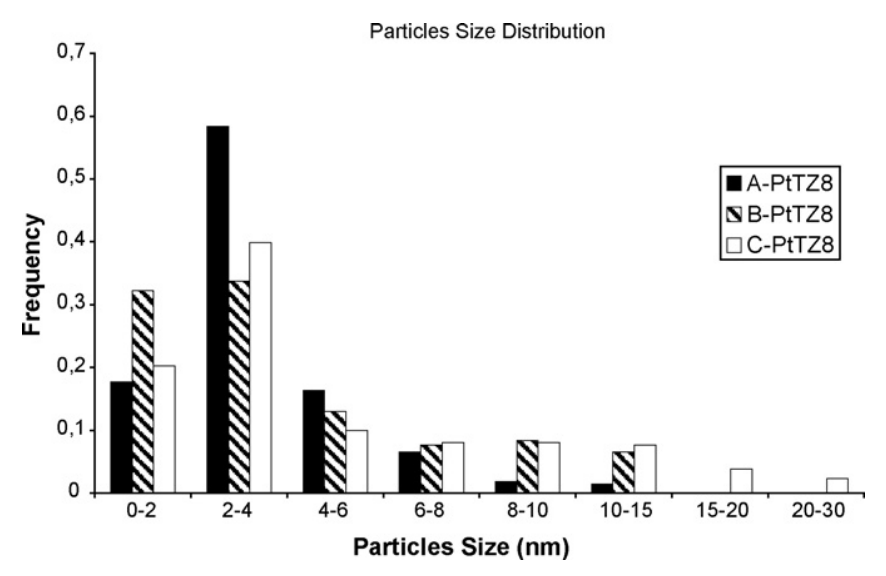

Fig. 2. Particles size distribution for Pt/YSZ catalysts obtained from more than 200 nanoparticles distributed in 5 images.

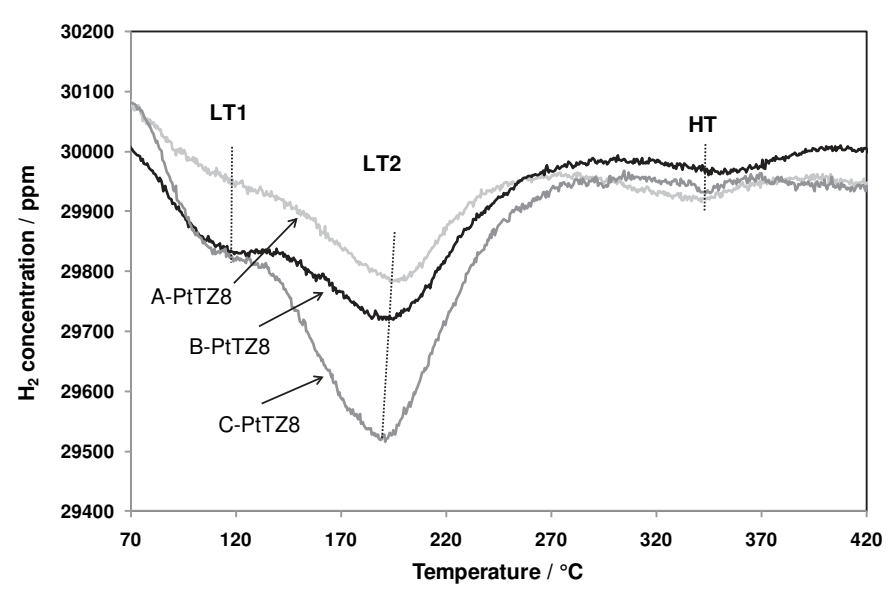

Fig. 3. TPR spectra of Pt/YSZ catalysts.

ues. The sample was reduced for $2 \mathrm{~h}$ at four different temperatures: $200,300,400$ and $500^{\circ} \mathrm{C}$. For each reducing treatment, the pulse $\mathrm{H}_{2}$ chemisorption was performed at $-28^{\circ} \mathrm{C}$ and $35^{\circ} \mathrm{C}$. The Pt dispersion was calculated considering a dissociative adsorption of $\mathrm{H}_{2}$ on a Pt surface atom leading to a stoichiometric ratio, Pt:H equal to 1 .

Table 3 reports the Pt dispersion values of B-PtTZ8 which has a range from $16 \%$ up to $41 \%$, i.e. a factor 2.5 . This result confirms the importance of temperature at which chemisorption is conducted as well as the pre-treatment temperature.

From a general point of view, hydrogen adsorption at $35^{\circ} \mathrm{C}$ gives high values of Pt dispersion. Referring to the TPR experiments, it is possible that these values are overestimated due to $\mathrm{H}_{2}$ spillover from Pt particles onto the YSZ surface as observed with TPR. Let us note that after a reducing treatment at $500^{\circ} \mathrm{C}$, the Pt dispersion value decreased. This seems to indicate that a high temperature reducing treatment can limit the $\mathrm{H}_{2}$ spillover as suggested by TPR experiments (Fig. 3).

Table 3

Pt dispersion values of B-PtTZ8 measured by $\mathrm{H}_{2}$ pulse chemisorption.

\begin{tabular}{llc}
\hline $\begin{array}{l}\text { Temperature of the } \\
\text { reducing pretreatment } \\
\left({ }^{\circ} \mathrm{C}\right)\end{array}$ & $\begin{array}{l}\text { Temperature of the } \mathrm{H}_{2} \text {-pulse } \\
\text { chemisorptions and corresponded } \\
\text { values of Pt dispersion }\end{array}$ \\
\cline { 2 - 3 } & $-28^{\circ} \mathrm{C}$ & $35^{\circ} \mathrm{C}$ \\
\hline 200 & $16 \pm 1 \%$ & $37 \pm 2 \%$ \\
300 & $24 \pm 1 \%$ & $41 \pm 2 \%$ \\
400 & $23 \pm 1 \%$ & $37 \pm 2 \%$ \\
500 & $21 \pm 1 \%$ & $27 \pm 1 \%$ \\
\hline
\end{tabular}




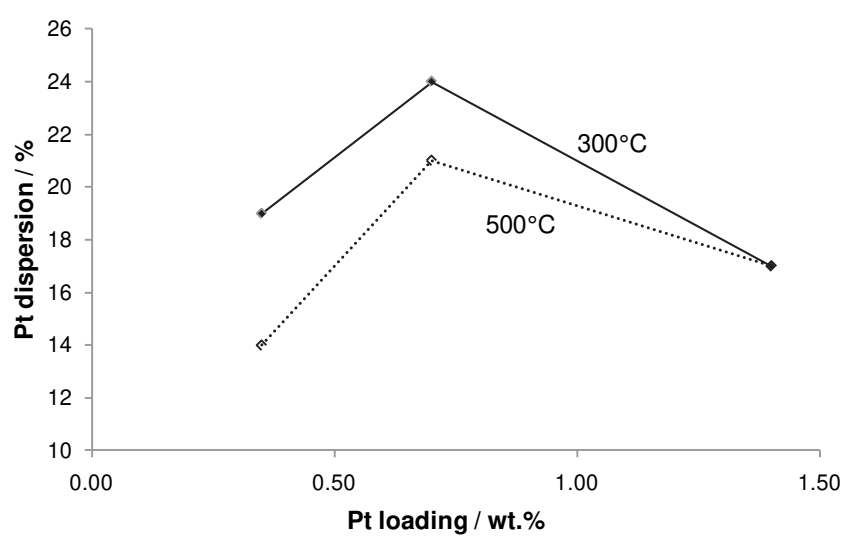

Fig. 4. Pt dispersion measured by $\mathrm{H}_{2}$-pulse chemisorption at $-28^{\circ} \mathrm{C}$ after prereduction of the samples at $300^{\circ} \mathrm{C}$ or $500^{\circ} \mathrm{C}$.

Pulse-chemisorption of hydrogen performed at $-28^{\circ} \mathrm{C}$ provided lower values of Pt dispersion. Excluding the value obtained after a reducing treatment at $200^{\circ} \mathrm{C}$, Pt dispersion measurements are fairly similar, in the range of $21-24 \%$. Decreasing the adsorption temperature inhibits the $\mathrm{H}_{2}$ spillover as already observed with ceria-based catalysts [2]. The low value of dispersion obtained after a reduction pre-treatment at $200{ }^{\circ} \mathrm{C}$ could be attributed to a non-complete Pt reduction as shown by TPR experiments (Fig. 3). Fig. 4 reports the Pt dispersion values of the three Pt/YSZ catalysts which were previously reduced at $300^{\circ} \mathrm{C}$ or $500^{\circ} \mathrm{C}$. Higher values of dispersion were found for a pre-treatment at $300^{\circ} \mathrm{C}$, suggesting the occurrence of the $\mathrm{H}_{2}$ spillover at $-28^{\circ} \mathrm{C}$. It is very interesting to notice that the impact of the pre-reduction temperature on the dispersion value decreased with the Pt loading. This observation is in good agreement with the HT TPR peak (Table 2) which also decreased with the Pt loading. According to Taimoor et al. [18], a step reduction in hydrogen of at least $350^{\circ} \mathrm{C}$ can lead to a significant concentration of Pt-carbonyl formed from the reduction of carbonates species initially present on the support. Therefore, a pre-reduction at $500^{\circ} \mathrm{C}$ is recommended to fully reduce Pt as well as to remove any carbonyl species formed in situ that could otherwise poison some sites of the reduced Pt.

Table 4 reports $\mathrm{Pt}$ dispersion values measured by $\mathrm{H}_{2}$-pulse chemisorption at $-28^{\circ} \mathrm{C}$ and $35^{\circ} \mathrm{C}$ for all catalysts. The reducing pre-treatment was performed at $500^{\circ} \mathrm{C}$. As expected, values recorded at $35^{\circ} \mathrm{C}$ instead of $-28^{\circ} \mathrm{C}$ are higher for all catalysts due to a more pronounced $\mathrm{H}_{2}$ spillover effect. The over-estimation of the Pt dispersion measured at $35^{\circ} \mathrm{C}$ is around $20-30 \%$ whatever the catalyst.

\subsection{Measurement of Pt dispersion by pulse CO-chemisorption}

The adsorption stoichiometry of $\mathrm{CO}$ on Pt is a well-known problem since $\mathrm{CO}$ can be linearly or bridge bonded on Pt. Nevertheless, we used pulse CO-chemisorption for the determination of Pt dispersions in order to compare with $\mathrm{H}_{2}$-pulse chemisorption. DRIFT (Diffuse Reflectance Infrared Fourier Transform) spectroscopy experiments were first performed in order to investigate the $\mathrm{CO}$ chemisorption on Pt/YSZ catalysts. Fig. 5 displays DRIFT spectra for

Table 4

Pt dispersion values of samples pre-reduced at $500{ }^{\circ} \mathrm{C}$.

\begin{tabular}{llll}
\hline \multirow{2}{*}{$\begin{array}{l}\text { Temperature of } \mathrm{H}_{2} \text { pulse } \\
\text { chemisorption }\left({ }^{\circ} \mathrm{C}\right)\end{array}$} & Pt dispersion & \\
\cline { 2 - 4 } & A-PtTZ8 & B-PtTZ8 & C-PtTZ8 \\
\hline-28 & $14 \pm 1 \%$ & $21 \pm 1 \%$ & $17 \pm 1 \%$ \\
35 & $18 \pm 1 \%$ & $27 \pm 1 \%$ & $24 \pm 1 \%$ \\
\hline
\end{tabular}

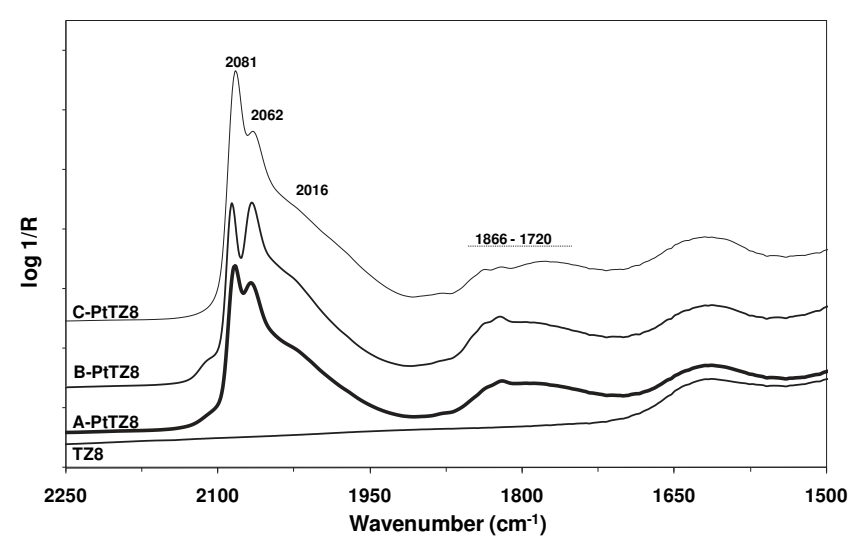

Fig. 5. DRIFT spectra of CO adsorption on all Pt/YSZ catalysts and bare support.

all catalysts as well as for the YSZ support itself recorded at $25^{\circ} \mathrm{C}$. Two predominant IR bands can be clearly distinguished at 2081 and $2062 \mathrm{~cm}^{-1}\left( \pm 5 \mathrm{~cm}^{-1}\right)$ with a large shoulder at lower wavelength centred at $\sim 2016 \mathrm{~cm}^{-1}\left( \pm 5 \mathrm{~cm}^{-1}\right)$, as well as a broad band region between 1866 and $1720 \mathrm{~cm}^{-1}$. All these IR bands do not appear on the DRIFT spectrum of the support itself. Therefore, they can only be attributed to $\mathrm{CO}$ chemisorption on Pt particles.

The sharp band at $2081 \mathrm{~cm}^{-1}$ is ascribed in the literature to the CO linearly bonded on Pt (111) while the second one, broader, at $2062 \mathrm{~cm}^{-1}$ is the CO linearly chemisorbed on Pt (100) as well as on Pt particle defects on the surface such as corners and edges [16,17]. According to Fox et al. [19] and Park et al. [20], the shoulder peak observed at $2016 \mathrm{~cm}^{-1}$ could indicate the presence of small platinum particles or defects. This shoulder at $2016 \mathrm{~cm}^{-1}$ is more pronounced on B-PtTZ8 sample which contains the highest quantity of small particles (diameter $<2 \mathrm{~nm}$ ) as shown by TEM observations (Fig. 2). A wide and weak band was identified at around $1866-1720 \mathrm{~cm}^{-1}$ which is attributed to bridge bonded $\mathrm{CO}$ in materials like $\mathrm{Pt} / \mathrm{SiO}_{2}$ and $\mathrm{Pt} / \mathrm{Al}_{2} \mathrm{O}_{3}$ [17]. The intensity and area of the three bands (at 2081, 2062 and $2016 \mathrm{~cm}^{-1}$ ) related to linearly bonded CO on Pt are much higher than those attributed to bridge bonded $\mathrm{CO}$. Therefore, we assumed an adsorption stoichiometric ratio Pt:CO equal to 1 in the interpretation of pulse-CO chemisorptions. Taking into account results achieved with pulse $\mathrm{H}_{2}$-chemisorption, the reducing pre-treatment of the samples was done at $500^{\circ} \mathrm{C}$ and pulse $\mathrm{CO}$-chemisorption was performed at $-28^{\circ} \mathrm{C}$. Table 5 shows the dispersion values obtained with both $\mathrm{H}_{2}$ and $\mathrm{CO}$ pulse chemisorption techniques. $\mathrm{CO}$ chemisorption resulted in very similar results for A-PtTZ8 and B-PtTZ8. For the sample C-PtTZ8, the Pt dispersion value is slightly lower. Analysing the dispersion results and correlating them with the TPR profiles and TEM images, one can conclude that reliable Pt dispersion measurements could be obtained by $\mathrm{H}_{2}$-pulse chemisorption at $-28^{\circ} \mathrm{C}$ preceded by a reducing treatment at $500^{\circ} \mathrm{C}$. The Pt dispersion values of the three Pt catalysts (Tables 4 and 5) are reasonable considering the low specific area of the YSZ support. The Pt dispersion rank of the three catalysts achieved by $\mathrm{H}_{2}$-pulse chemisorption (B-PtTZ8 $>$ CPtTZ8 > A-PtTZ8) is different from that calculated from the statistic analysis of the TEM images (Fig. 2). This underlines the difficulty

Table 5

Pt dispersion values measured by $\mathrm{H}_{2}$ and $\mathrm{CO}$ pulse chemisorptions at $-28^{\circ} \mathrm{C}$ (reducing pretreatment at $500^{\circ} \mathrm{C}$ ).

\begin{tabular}{lll}
\hline Samples & $\begin{array}{l}\text { Pt dispersion measured by } \\
\mathrm{H}_{2} \text { pulse chemisorption }\end{array}$ & $\begin{array}{l}\text { Pt dispersion measured by } \\
\text { CO pulse chemisorption }\end{array}$ \\
\hline A-PtTZ8 & $14 \pm 1 \%$ & $13 \pm 1 \%$ \\
B-PtTZ8 & $21 \pm 1 \%$ & $22 \pm 1 \%$ \\
C-PtTZ8 & $17 \pm 1 \%$ & $14 \pm 1 \%$ \\
\hline
\end{tabular}




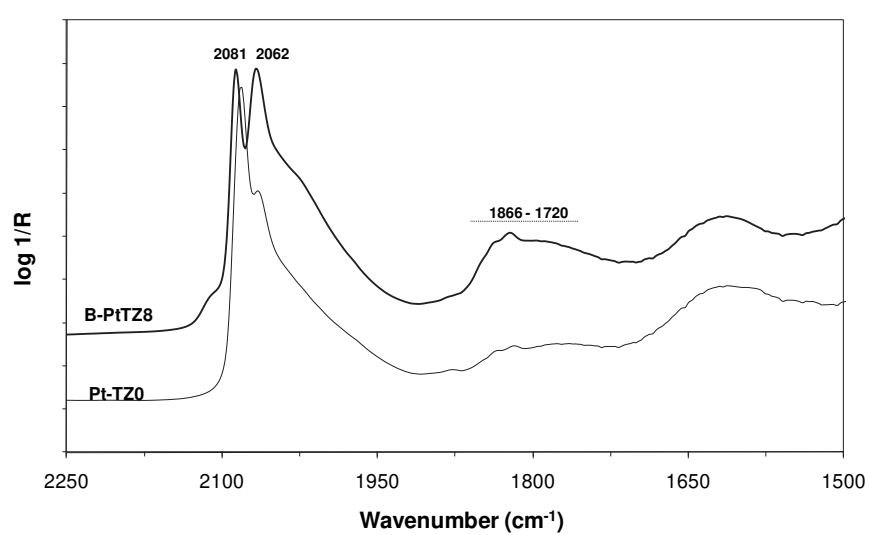

Fig. 6. DRIFT spectra of CO adsorption on B-PtTZ8 and Pt-TZO.

to deduce reliable Pt dispersion from TEM observations with samples containing a heterogeneous distribution of metal particle size and shows the relevance of the present study. Nevertheless, let us not that Pt dispersion determined from $\mathrm{H}_{2}$-pulse chemisorption follows the same rank than the mean diameter determined by TEM considering only the small particles (in the range $0-4 \mathrm{~nm}$ ). This correlation can be explained by a statistic error on the particle size distribution which increases with the size. Indeed, the concentration of small particles, in the range $0-4 \mathrm{~nm}$, is predominant representing at least $60 \%$ of the particles (Fig. 2). On the opposite, the proportion of large particles (in the range $10-30 \mathrm{~nm}$ ) does not exceed $20 \%$. Therefore, the statistic error on the particle size distribution based on only 200 particles is much higher on large particles than on small ones.

Regarding DRIFT experiments, we have focused our attention to the IR bands at $2081 \mathrm{~cm}^{-1}$ and $2062 \mathrm{~cm}^{-1}$. As shown by Sirita et al. [21], quantitative comparisons between two DRIFT spectra recorded on different samples cannot be made because variations of absorptivity, reflectivity, particle shape and packing can affect the effective optical pathlenght in the sample. Nevertheless, we used similar catalysts based on the same support TZ8 or on very similar one, i.e. $\mathrm{ZrO}_{2}$. Fig. 6 compares DRIFT spectra of $\mathrm{CO}$ chemisorption at $25{ }^{\circ} \mathrm{C}$ on B-PtTZ8 and Pt/ZrO ${ }_{2}$ (denoted as Pt-TZ0) catalysts (Table 1). The Pt loading and dispersion (26\%) as well as the specific area of Pt-TZ0 are very similar to those of B-PtTZ8 (Table 1). Even, if the effective optical pathlenght is different from a sample to another one, on could try to consider that significant differences of ratios between areas of two DRIFT bands at 2062 and $2081 \mathrm{~cm}^{-1}$ (measured on the same sample) can be compared. Fig. 6 shows that the intensity and area of the band at $2062 \mathrm{~cm}^{-1}$ are significantly lower on the Pt-TZ0 sample. The ratio between the area of the band at $2081 \mathrm{~cm}^{-1}$ and that of the band at $2062 \mathrm{~cm}^{-1}$ varies from 1.2 on Pt-TZ0 up to 2.5 on B-PtTZ8. This significant difference of a factor 2 was reproduced by recording additional DRIFT spectra with other batches of these two catalyst, i.e. Pt-TZO and B-Pt-TZ8. Nonsubstituted zirconia contains a significantly less amount of oxygen vacancies than TZ8. Indeed, oxygen vacancies in TZ8 are formed from the $\mathrm{Zr}^{4+}$ substitution by $\mathrm{Y}^{3+}$ cations. This could indicate that the band observed at $2062 \mathrm{~cm}^{-1}$ is linked to the presence of oxygen vacancies on the support. One can postulate the existence of CO molecules bridged between a Pt atom and an oxygen vacancy or of strong electronic interactions between oxygen vacancy and a molecule of $\mathrm{CO}$ bonded to a neighboured Pt atom. One can compare CO species attributed to the band at $2062 \mathrm{~cm}^{-1}$ with the LT1 TPR peak which was also linked to oxygen vacancies. The ratio between the areas of the IR bands at 2062 and $2081 \mathrm{~cm}^{-1}$ were estimated and compared to the concentration values of oxygen vacancies in interaction with Pt particles determined from the LT1 TPR peak

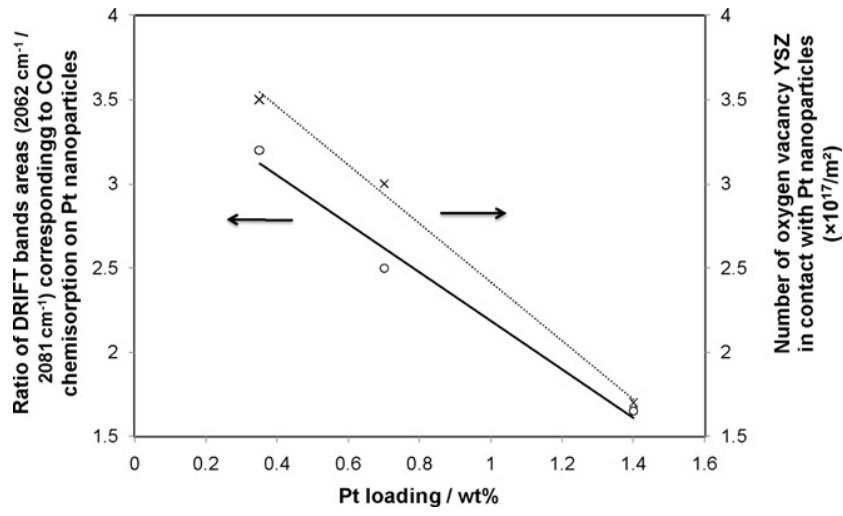

Fig. 7. Variations of the ratio between the areas of the IR bands at 2062 and $2081 \mathrm{~cm}^{-1}$ determined by DRIFT as well as the concentration values of oxygen vacancies determined by TPR as a function of the Pt loading.

(Table 2). Fig. 7 shows that the variations of these two parameters follow the same trend, confirming the relationship between the IR band at $2062 \mathrm{~cm}^{-1}$ and the oxygen vacancies concentration. Therefore, these results seem to indicate that oxygen vacancies on the support interact with Pt particles and have an impact on both hydrogen and $\mathrm{CO}$ adsorptions.

\subsection{Measurement of Pt dispersion by static volumetric titration}

Static volumetric titration was also used to measure the Pt dispersion in order to compare with the results obtained with $\mathrm{H}_{2}$-pulse chemisorption. Volumetric titrations were performed with a gasadsorption measuring unit (Belsorp-max, Bel Japan), which is based on the constant volume method. Hydrogen chemisorption was used to measure the dispersion of platinum and the double isotherm method was used as described by Perrichon et al. [2]. This method consists in performing two successive isotherms, with an intermediate treatment for $30 \mathrm{~min}$ under vacuum at $25^{\circ} \mathrm{C}$. The subtraction of the two isotherms allows determining the irreversibly bound chemisorbed hydrogen (HCirrev), which corresponds to hydrogen adsorbed on the metal surface. The first isotherm gives the total amount of chemisorbed hydrogen (HCtot) while the second one gives the reversible part ( $\mathrm{HCrev}$ ). The difference between these two isotherms gives the irreversible part of chemisorbed hydrogen (HCirrev).

The sample B-PtTZ8 was pre-treated at $500^{\circ} \mathrm{C}$ for $2 \mathrm{~h}$ in $\mathrm{H}_{2}$. Hydrogen chemisorption was performed at $-78^{\circ} \mathrm{C}$ in order to avoid $\mathrm{H}_{2}$ spillover on the support as proposed by Perrichon et al. [2]. This temperature was obtained by maintaining the cell in a mixture of acetone and carbon dioxide ice. As for $\mathrm{H}_{2}$ pulse chemisorption, the chemisorption of hydrogen over Pt was considered as dissociative, leading to a stoichiometric ratio, $\mathrm{Pt}: \mathrm{H}$ equal to 1 . The extrapolation of the irreversible isotherm (HCirrev) plateau to the pressure zero gives the maximum quantity of hydrogen irreversibly adsorbed on $\mathrm{Pt}$, which allows determining the quantity of surface platinum and then the dispersion. The Pt dispersion of the catalyst B-PtTZ8 was found to be $20.5 \%$. This value is in very good agreement with the one obtained by hydrogen pulse chemisorption, i.e. $21 \pm 1 \%$. This result confirms that fast and reliable Pt dispersion measurements of Pt/YSZ catalysts can be obtained by $\mathrm{H}_{2}$-pulse chemisorption at $-28^{\circ} \mathrm{C}$ preceded by a reducing treatment at $500^{\circ} \mathrm{C}$.

\section{Conclusions}

Yttria-Stabilised Zirconia is an ionically conducting material which is widely regarded as an attractive alternative catalytic support. The aim of this study was to determine a reliable procedure 
to measure the dispersion of Pt nanoparticles supported on YSZ. A $\mathrm{H}_{2}$ pulse chemisorption technique was used at various temperatures. In addition, Temperature Programmed Reduction (TPR) experiments were performed to characterize the pre-reduction step of the catalysts before dispersion measurements. A fast and reliable procedure was defined consisting of a pre-reduction step in hydrogen at $500^{\circ} \mathrm{C}$ and a $\mathrm{H}_{2}$ pulse chemisorption at $-28^{\circ} \mathrm{C}$. Reproducible Pt dispersion values were obtained in good agreement with those measured by pulse $\mathrm{CO}$ chemisorption and static volumetric titration. The combination of Diffuse Reflectance Infrared Fourier Transform (DRIFT) spectroscopy and TPR characterized the role of surface oxygen vacancies on the YSZ support for $\mathrm{H}_{2}$ and $\mathrm{CO}$ chemisorptions.

\section{References}

[1] G. Ertl, H. Knözinger, F. Schüth, J. Weitkamp (Eds.), Handbook of Heterogeneous Catalysis, vol. 1, Wiley-VCH, 2008, pp. 1-14.

[2] V. Perrichon, L. Retailleau, P. Bazin, M. Daturi, J.C. Lavalley, Appl. Catal. A 260 (2004) 1-8

[3] G. Ertl, H. Knözinger, F. Schüth, J. Weitkamp (Eds.), Handbook of Heterogeneous Catalysis, vol. 2, Wiley-VCH, 2008, pp. 738-763.
[4] T. Shishido, H. Hattori, Appl. Catal. A: Gen. 146 (1996) 157-164

[5] E.C. Subbarao, H.S. Maiti, Solid State Ionics 11 (1984) 317-338.

[6] C.G. Vayenas, S. Bebelis, C. Pliangos, S. Brosda, D. Tsiplakides, Electrochemical Activation of Catalysis: Promotion. Electrochemical Promotion and MetalSupport Interactions, Kluwer Academic Publishers/Plenum Press, New York, 2001

[7] S.J. Tauster, S.C. Fung, J. Catal. 55 (1978) 29-35.

[8] C.G. Vayenas, S. Brosda, C. Pliangos, J. Catal. 216 (2003) 487-504.

[9] G.L. Haller, J. Catal. 216 (2003) 12-22.

[10] P. Vernoux, M. Guth, X. Li, Electrochem. Solid Sate Lett. 12 (2009) E9-E11.

11] Y.-Z. Chen, B.-J. Liaw, C.-F. Kao, J.-C. Kuo, Appl. Catal. A 217 (2001) 23-31.

12] M.-Y. He, J.G. Ekerdt, J. Catal. 87 (1984) 238-254.

[13] W.-P. Dow, Y.P. Wang, T.-J. Huang, J. Catal. 160 (1996) 155-170.

[14] S. Benard, L. Retailleau, F. Gaillard, P. Vernoux, A. Giroir-Fendler, Appl. Catal. B 55 (2005) 11-21.

[15] A. Katsaounis, Z. Nikopoulou, X.E. Verykios, C.G. Vayenas, J. Catal. 222 (2004) 192-206.

[16] P. Pillonel, S. Derrouiche, A. Bourane, F. Gaillard, P. Vernoux, D. Bianchi, Appl. Catal. A 278 (2005) 223-231.

[17] M.A. Vannice, C.C. Twu, S.H. Moon, J. Catal. 79 (1983) 70-80.

[18] A.A. Taimoor, I. Pitault, F.C. Meunier, J. Catal. 278 (2011) 153-161.

[19] S.G. Fox, V.M. Browne, P. Hollins, J. Electron Spectrosc. Related Phenom. 54/55 (1990) 749-758.

[20] S. Park, A. Wasileski, M.J. Weaver, J. Phys. Chem. B 105 (2001) 97199725

[21] J. Sirita, S. Phanichphant, F.C. Meunier, Anal. Chem. 79 (2007) 3912-3918. 